\title{
Pedagogias universitárias: as influências das diferentes áreas do conhecimento na atuação docente
}

\author{
Greice Scremin ${ }^{1}$ \\ Silvia Maria de Aguiar Isaia ${ }^{1}$
}

\section{Resumo}

Este artigo tem o objetivo de discutir a influência das diferentes áreas do conhecimento na pedagogia universitária. A linha metodológica, de cunho qualitativo-narrativo, teve por base o corpus constituído pelas narrativas de 60 professores das diferentes áreas (de acordo com a classificação do $\mathrm{CNPq}$ ), de uma universidade pública do interior do Rio Grande do Sul (Brasil). A análise das narrativas seguiu os princípios da Análise Textual Discursiva. Como resultado, a investigação permitiu a vivência de um espaço de formação de pesquisadores no contexto de um grupo de pesquisa, pois o fato de pesquisadores de diferentes áreas do conhecimento fazerem parte desse grupo favoreceu a diversidade de formas de interpretação e de organização da análise dos achados da pesquisa. No que tange ao processo de interpretação dos achados, as categorias de análise construídas compreenderam: conhecimento específıco como balizador da docência; rede de saberes da área profissional; docência em ação. Essas três categorias apresentaram-se permeadas por um núcleo fundante (supra-categoria), ao qual se denominou dimensão pessoal da docência, demarcando, assim, a atuação docente. Foi possível constatar que o conhecimento pedagógico se ajusta às diferentes áreas do conhecimento, tomando corpo como um conhecimento pedagógico específico. Isso acaba por afirmar e imprimir uma característica de estrutura epistemológica própria do conhecimento pedagógico.

\section{Palavras-chave}

Pedagogias universitárias - Atuação docente - Áreas de conhecimento - Saber acadêmico.

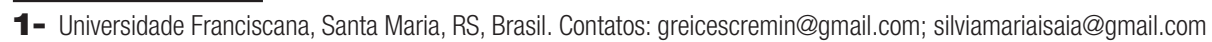




\section{University pedagogies: the influence of different areas of knowledge on teaching performance}

\section{Abstract}

This article aims to discuss the influence of different areas of knowledge on university pedagogy. The qualitative-narrative methodological approach was based on the corpus consisting of the narratives of 60 teachers from different areas (according to the CNPq classification), from a public university in the countryside of Rio Grande do Sul (Brazil). The analysis of the narratives complied with the principles of Discursive Textual Analysis. As results, the research allowed for the experience of a space to train researchers in the context of a research group, due to the fact that researchers from different areas of knowledge are members of this group, which favored the diversity of forms of interpretation and organization of the analysis of the research findings. Regarding the process of interpreting the findings, the categories of analysis constructed included: specific knowledge as a teacher's guide; network of knowledge of the professional area; teaching in action. These three categories were permeated by a founding nucleus (supra category) which was called the personal dimension of teaching, thus distinguishing the teaching performance. It was possible to verify that the pedagogical knowledge is adjusted to the different areas of knowledge, taking shape as a specific pedagogical knowledge. This eventually asserts and boosts a characteristic of epistemological structure suitable to the pedagogical knowledge.

\section{Keywords}

University pedagogies - Teaching performance - Knowledge areas - Academic skills.

\section{Palavras iniciais...}

Este trabalho decorre dos resultados da pesquisa Os Movimentos da Docência Superior: especificidades nas diferentes áreas de conhecimento e sua influência na atuação docente ${ }^{2}$ (ISAIA; ROCHA, 2013), que envolveu a relação existente entre as áreas do conhecimento e os Movimentos da Docência Superior (MDS).

As áreas do conhecimento relacionadas na pesquisa dizem respeito à classificação do CNPq quanto às atividades desenvolvidas em Unidades Universitárias e Departamentos Didáticos de uma Instituição de Ensino Superior (IES) pública federal do interior do estado do Rio Grande do Sul (Brasil).

Entendemos que os Movimentos da Docência Superior constituem um processo que compreende os diferentes momentos da carreira docente, envolvendo a trajetória vivencial dos professores e o modo como eles articulam o pessoal, o profissional e o

2- Pesquisa financiada pelo Conselho Nacional de Desenvolvimento Científico e Tecnológico (CNPq); Edital Produtividade em Pesquisa - PQ/2012. 
institucional, bem como o modo pelo qual, consequentemente, vão se (trans)formando no decorrer do tempo (ISAIA; ROCHA, 2013). Os movimentos, assim configurados, carregam as peculiaridades de cada docente e de como ele interpreta os acontecimentos vividos; o modo como, a partir das marcas dessas trajetórias, enfrentam e concebem a docência; a contextualização epistemológica das áreas específicas de conhecimento e do saber acadêmico a que esses sujeitos estão ligados; e de que maneira podem articular os diversos saberes e fazeres próprios à construção da docência, evidenciando ou não a possibilidade de uma produção pedagógica.

Assim, a docência superior apoia-se na dinâmica da interação de diferentes processos que respaldam o modo como os professores concebem o conhecer, o fazer, o ensinar e o aprender, bem como o significado que dão a eles (ISAIA, 2006b). Corroborando essa afirmativa, entendemos a atuação docente como um processo complexo e multifacetado que integra atividades diversificadas como ensino, pesquisa, extensão e gestão, assim como todas as demais funções exercidas pelos docentes da educação superior.

No que tange à atuação docente, Viscovini et al. (2009, p. 1231) afirmam que

[...] as diferentes formas de atuação dos professores devem ser pensadas e discutidas tomando-se como referência os fatores sociais, políticos e históricos que oferecem ao homem os valores necessários para interpretar as questões que estão postas. Num exercício teórico, somos instigados a compreender as diversas situações que promovem a educação, sobretudo a concepção que se tem sobre a formação e atuação docente.

Ou seja, a atuação docente envolve uma reflexão em uma perspectiva histórica acerca do significado do ato educativo, relacionando tal ato com o desenvolvimento do conhecimento do ser humano, pois este é parte da sociedade que se caracteriza pela dinâmica de suas transformações. Nessa pesquisa, ficou claro que as formas de pensar e organizar a atuação docente estão diretamente relacionadas com o tipo de paradigma educacional no qual os docentes vivenciaram a sua formação na área específica.

Nessa perspectiva, tendo como fio condutor a atuação docente e as áreas específicas de conhecimento dos professores participantes, este artigo tem o objetivo de discutir as influências das diferentes áreas do conhecimento na pedagogia universitária.

Para tanto, entendemos ser necessário destacar as peculiaridades do conhecimento científıco e do saber acadêmico. No caso do conhecimento científıco, o processo de produção exige uma série de critérios de rigor em que precisam ser consideradas condições espaço-temporais concretas, envolvendo uma situação problematizadora, uma relação próxima entre o sujeito e o objeto, a explicitação dos processos e das formas da construção - lógica de construção do conhecimento, envolvendo tanto as questões quanto as respostas delas decorrentes. As respostas ou resultados obtidos desses processos passam também por critérios coletivos de verificação ou justificativa (GAMBOA, 2009).

Por outro lado, para Gamboa (2009), a acumulação de repostas sobre um determinado fenômeno, de informações diferentes sobre algo, constitui o mundo dos saberes. Essas respostas podem ser divulgadas na forma de informações padronizadas e selecionadas, 
livros didáticos, esquemas, resumos e fórmulas, sendo traduzidas para o contexto acadêmico. A esse complexo denominamos saberes acadêmicos.

A característica dos saberes é a de se apresentarem como respostas, separadas das suas perguntas originárias. Nesse sentido, os saberes são produtos que não exigem sua relação imediata com o processo de pergunta/resposta, inerente ao conhecimento científico. Assim, quando falamos em áreas específicas de conhecimento, estamos considerando também os saberes acadêmicos delas decorrentes, que são trabalhados no processo da docência. Portanto, o saber acadêmico envolve a sistematização e a estratificação do conhecimento científico, dando origem às disciplinas específicas dos diversos cursos desenvolvidos na universidade.

Para a compreensão da atuação docente, é importante levar em consideração sua especificidade no contexto do conhecimento específico e do saber acadêmico. Ambos representam a base epistemológica na qual transita o ofício de ser professor.

Nesse contexto, a atuação docente pode ser vista, de acordo com Shulman (1968, 1987, 1989), a partir de três dimensões: a do conhecimento do conteúdo específico, ou seja, a de conceitos básicos de determinada área, o que implica o modo de entender seu processo de construção (conhecimento científico e saber acadêmico); a do conhecimento pedagógico geral, ou seja, incluindo objetivos, metas e propósitos educacionais, de manejo de classe e interação com os alunos, de estratégias instrucionais, de como os alunos aprendem, de outros conteúdos, de conhecimento curricular; e, ainda, a do conhecimento pedagógico do conteúdo, que integra tanto o conteúdo específico, quanto o pedagógico de cunho geral, envolvendo o modo como o professor concebe os propósitos de ensinar determinado conteúdo, o que é importante que os alunos aprendam, as possíveis concepções errôneas ou falsas que eles apresentam em relação a esse conteúdo, entre outros aspectos.

Nessas três dimensões - mas, de modo especial, na primeira e na última -, a área específica de conhecimento à qual o professor está vinculado e os saberes acadêmicos daí resultantes podem direcionar a atuação docente, isto é, como cada professor constitui seu modo de ser professor e, consequentemente, produz sua atuação docente.

Assim sendo, este texto apresenta a seguir o caminho metodológico, onde estão descritas as ações de análise realizadas pelo grupo de pesquisa. Posteriormente, apresentamos os resultados e as discussões à luz das teorias estudadas como suporte para nossas interpretações.

\section{Caminho metodológico...}

A questão norteadora do estudo tratou de identificar: que especificidades apresentam os Movimentos da Docência Superior (MDS) nas diferentes áreas do conhecimento e como estes influenciam na atuação docente? Para o desenvolvimento da pesquisa, optamos por uma investigação pautada em uma abordagem de cunho narrativo (CONNELLY; CLANDININ, 1995; McEWAN, 1998; BOLÍVAR; DOMING0; FERNÁNDEZ, 2001; GOODSON, 2004), por entendermos a linguagem como instrumento vivo de comunicação, ação e interpretação de caráter intersubjetivo (HABERMAS, 1987a, 1987b; RICOEUR, 1978). 
Desse modo, a partir do narrado e do interpretado podemos resgatar um conhecimento mais próximo ao mundo da vida dos professores e à realidade educativa na qual estão inseridos, para compreendê-los como pessoas e profissionais, valorizando as experiências formativas por eles vivenciadas. Pode ser compreendido como um horizonte comunicacional que permeia todos os processos de entendimento humano:

Um mundo da vida constitui, como temos visto, o horizonte de processos de entendimento com que os implicados chegam a um acordo ou discutem sobre algo pertencente ao mundo objetivo, ao mundo social que partilham, ou ao mundo subjetivo de cada um. (HABERMAS, 1987a, p. 184).

Nesse sentido, o estudo partiu das narrativas dos sujeitos participantes, o que nos permitiu apreender como os professores constituem sua atuação docente, tendo em vista suas áreas de conhecimento. Arnaus (1995) considera a dinâmica entre os que contam (narram e interpretam) e os que interpretam (interpretação a partir da interpretação realizada pelos contadores) como um movimento de dupla direção.

As narrativas docentes, assim compreendidas, representam o diálogo interdiscursivo e intersubjetivo capaz de viabilizar uma compreensão mais apurada da construção da atuação docente e do interjogo das áreas de conhecimento. Esse processo pode ser apreendido por meio da Matriz Categorial da Investigação que compreende o design da investigação, definindo a coerência entre o problema de pesquisa, os objetivos (geral e específicos), os eixos norteadores e os indicadores específicos que orientam a condução da pesquisa. A Matriz Categorial da Investigação organizou, portanto, o espaço de interlocução entre as falas/dizeres/narrativas dos professores.

A entrevista narrativa contou com uma matriz guia que orientou as narrativas dos professores a partir de três grandes eixos: área do conhecimento científico; articulação entre conhecimento científico e o saber acadêmico; saber acadêmico em ação.

Em termos de interpretação analítica das narrativas dos professores, escolhemos como ponto de partida o método de Análise Textual Discursiva (MORAES; GALIAZZI, 2007; BAUER; GASKELL, 2004), partindo de quadros de análise das entrevistas dos 60 sujeitos para inferirmos quais as especificidades dos MDS, segundo as áreas de conhecimento, e para identificar os principais marcadores encontrados. Ao mesmo tempo, estivemos atentos ao modo como os professores narram sua atuação docente, a fim de descobrirmos as influências decorrentes de suas áreas de conhecimento.

Os sujeitos da pesquisa foram 60 professores oriundos das áreas específicas de conhecimento, conforme classificação do CNPq: ciências exatas e da terra; ciências biológicas; engenharias; ciências da saúde; ciências agrárias; ciências sociais e aplicadas; ciências humanas; linguística e letras, envolvendo cursos de licenciatura e bacharelado da instituição pública participante. Selecionamos os professores em função do número em cada Unidade Universitária e em função das áreas de conhecimento do CNPq, visando a constituir um grupo harmônico em termos de representatividade em cada área e tempo de experiência. Dessa forma, chegamos a uma amostra total de 60 docentes: (60/1.094) x $100=5,5 \%$ do total de docentes da IES pesquisada. 
A análise das entrevistas narrativas teve como procedimentos a base apresentada por Moraes e Galiazzi (2007) para a Análise Textual Discursiva, descrita a partir dos seguintes elementos: a desmontagem dos textos (unitarização), o estabelecimento de relações (categorização), a captação do novo emergente e a auto-organização.

$\mathrm{Na}$ desmontagem dos textos, há a desconstrução do texto analisado; essa fase é marcada como um caminho para o caos (MORAES, 2003). Chamado de unitarização, tal elemento possibilita o exame do material em seus detalhes, viabilizando a fragmentação para o alcance de unidades constituintes, levando em consideração os interesses da pesquisa. A fase de estabelecimento de relações foi momento da categorização, viabilizando a construção de relações entre as unidades de base, destacando combinações e classificações para compreender como esses dados mais unitários podem se reunir em categorias e conjuntos mais complexos. A ATD demarca um processo de comparação e de agrupamento constante, com a seleção de dados organizados conforme características semelhantes, sempre sob o olhar atento de quem analisa. A partir dessas categorias é que foi possivel compor o metatexto, que constituiu a última etapa e fomentou a representação dos novos entendimentos possibilitados pela análise.

Esse processo foi realizado nas distintas fases de análise desenvolvidas pelo grupo. Devido ao grande número de entrevistas narrativas a serem analisadas e ao número de pessoas integrantes do grupo de pesquisa, optou-se por organizar a análise em duas grandes etapas:

- $1^{\text {a }}$ Análise - Preliminar: na qual as transcrições das entrevistas foram distribuídas aleatoriamente entre todos os membros do grupo para que fosse realizada uma leitura criteriosa, a fim de identificar excertos que pudessem ser interessantes de serem alocados em cada indicador da Matriz da Investigação. Essa etapa foi necessária para que os pesquisadores pudessem identificar novos excertos, corroborar os excertos já selecionados ou discordar dos excertos eleitos por outros colegas (na análise já realizada na pesquisa anterior).

- 2a Análise - Por área de conhecimento: o Grupo de Pesquisa Trajetórias de Formação (GTFORMA) ${ }^{3}$ foi dividido em 4 subgrupos (A - Ciências Agrárias e Engenharias; B - Ciências Humanas e Linguística, Letras e Artes; C - Ciências Exatas e da Terra e Ciências Sociais e Aplicadas; D - Ciências da Saúde e Ciências Biológicas), cada grupo, em média, com cinco participantes. Tais subgrupos foram orientados a realizar a análise de cada uma das entrevistas recebidas, levando em conta as áreas do conhecimento (esse processo levou aproximadamente três meses). Posteriormente, cada subgrupo deveria comparar todas as análises dos sujeitos dentro da mesma área e elaborar uma síntese envolvendo os indicadores da Matriz da Investigação para ser novamente discutida no grande grupo (GTFORMA) (esse processo levou aproximadamente um mês). As sínteses por área de conhecimento foram apresentadas e discutidas no âmbito do GTFORMA. Os subgrupos reuniram-se outra vez a fim de que, a partir das discussões do grande grupo, pudessem esboçar pré-categorias de análise por área de conhecimento. Novamente, os subgrupos

3- Grupo de Pesquisa Trajetórias de Formação, aprovado no CNPq desde o ano de 2002. 
apresentaram e discutiram tais pré-categorias com todo o GTFORMA. Para essa etapa, foi solicitado que cada subgrupo descrevesse o caminho analítico desenvolvido, bem como as pré-categorias encontradas em um relatório. A partir dos relatórios produzidos por cada subgrupo, foram realizadas discussões no GTFORMA a fim de compilar as pré-categorias em categorias gerais resultantes da análise realizada.

\section{Resultados e discussões}

As narrativas analisadas foram, como já mencionado, organizadas por área de conhecimento do CNPq. Assim, os sujeitos estiveram classificados conforme as áreas do conhecimento, as Unidades Universitárias e os Departamentos de lotação na IES. Cada sujeito recebeu um código, sendo designados de S1 até S60.

Para o andamento da atividade analítica, fez-se necessário que cada subgrupo tivesse autonomia para organizar suas ações de análise. Dessa forma, os subgrupos apresentaram percursos analíticos distintos, conforme é possível visualizar na Figura 1:

Figura 1 - Processo de análise por área de conhecimento (por subgrupo)
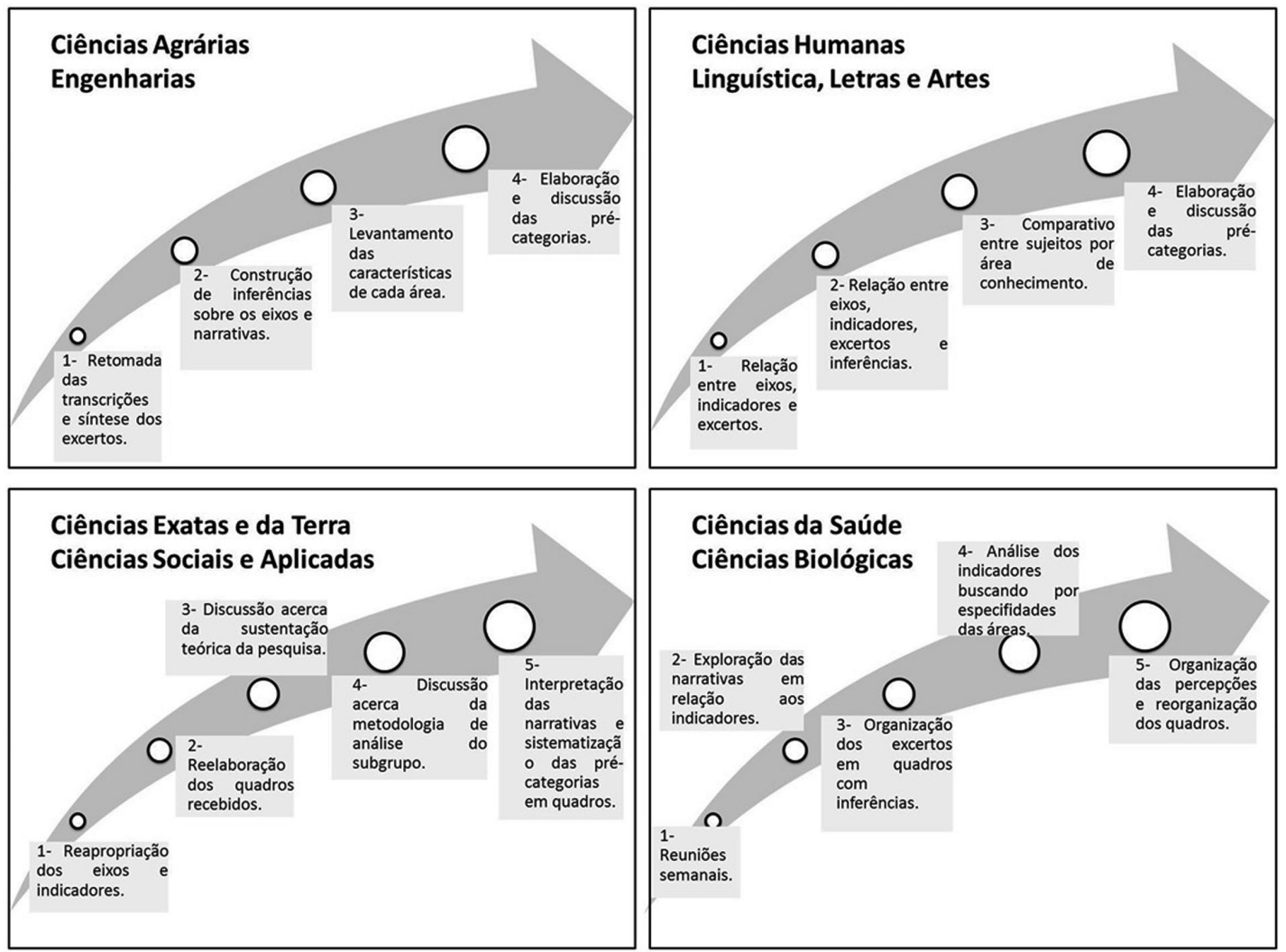

Fonte: Elaborada pelas autoras. 
Observamos que, apesar de os subgrupos terem autonomia, há certa similaridade na forma como buscaram sistematizar as análises, tendo em vista as etapas da Análise Textual Discursiva (MORAES; GALIAZZI, 2007). Entretanto, os achados e a interpretação a respeito deles foram peculiares a cada grupo, levando em conta as áreas do conhecimento. Conforme podemos identificar, há subgrupos que realizaram a categorização subdividindo as áreas analisadas e outros que conseguiram agrupá-las. Outros, ainda, seguiram a lógica da Matriz da Entrevista Narrativa como guia para sistematizar as pré-categorias. Assim sendo, apresentamos no Quadro 1 as pré-categorias elencadas por cada subgrupo.

É possível observar que até mesmo a nomenclatura das pré-categorias é distinta, pois alguns subgrupos organizaram a nomenclatura de acordo com os eixos da Matriz da Entrevista Narrativa; outros, de forma mais abrangente, utilizaram uma indicação temática. E outros, ainda, foram mais específicos na nomenclatura, tendo em vista características bem específicas das áreas de conhecimento.

A partir das pré-categorias identificadas pelos subgrupos, foi possível agrupar os achados em três categorias fundamentais e um núcleo fundante (supra-categoria), conforme a Figura 2.

Figura 2 - Sistematização das categorias de análise

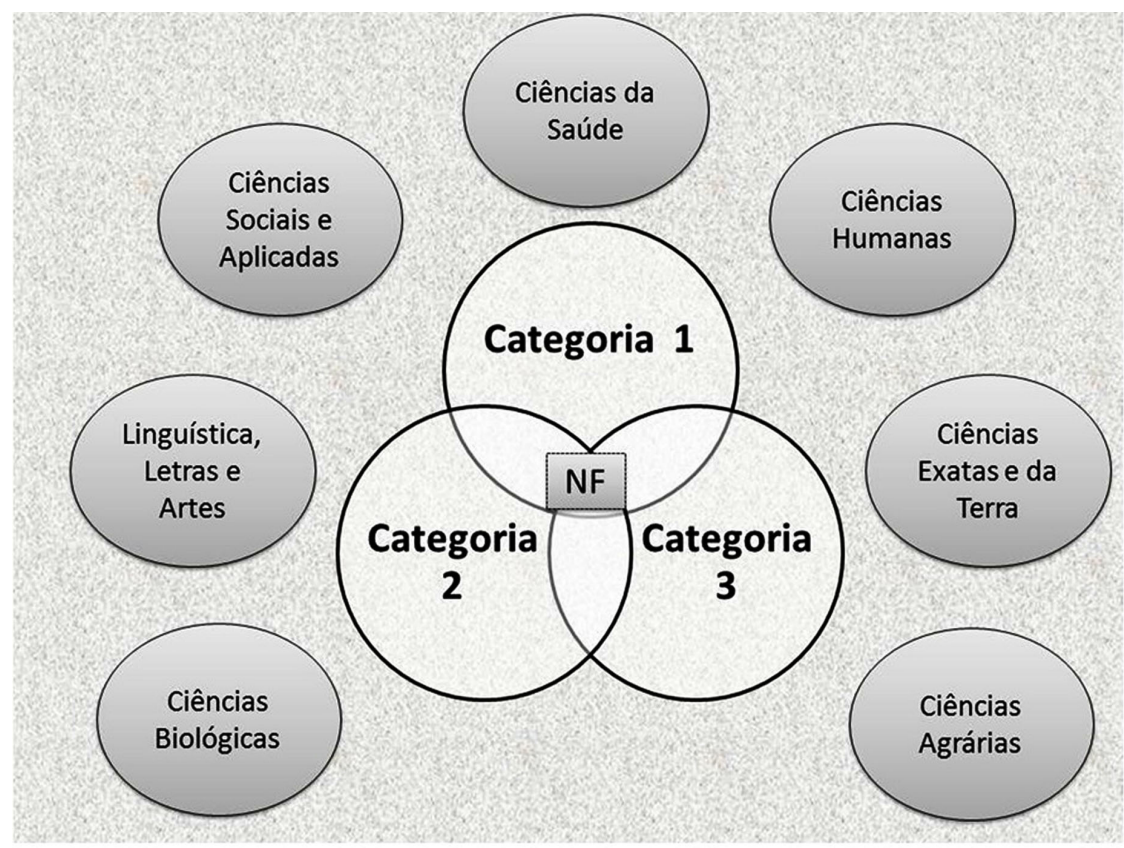

Representação da figura

Categoria 1: Conhecimento específico como balizador da docência

Categoria 2: Rede de saberes da área profissional

Categoria 3: Docência em ação

Núcleo fundante (NF) - supra-categoria: Dimensão pessoal da docência

Áreas de conhecimento: conforme classificação do CNPq

Fonte: Elaborada pelas autoras. 


\section{Quadro 1- Pré-categorias por subgrupo}

\begin{tabular}{|c|c|}
\hline 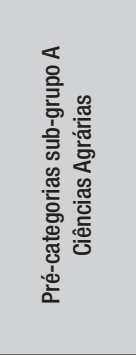 & $\begin{array}{l}\text { I. Método tradicional de ensino: Demonstraram características do modelo de ensino tradicional, tanto no planejamento quanto na prática docente. } \\
\text { II. Atuação docente alicerçada na experiência prévia como profissional da área específica: Experiências prévias à carreira como docente, no } \\
\text { campo de atuação profissional específica. A maioria dos docentes entrevistados desta área ingressou na universidade há mais de } 15 \text { anos, em } \\
\text { uma época em que cursar uma pós-graduação não era visto como necessidade primeira, pois não era tão difundido e valorizado. } \\
\text { III. Aspectos humanos para a formação dos acadêmicos: Docentes sinalizaram em suas falas a importância de se pensar que, apesar de } \\
\text { trabalharem com máquinas ou animais, antes de tudo, é preciso considerar o ser humano que está por trás da situação. } \\
\text { IV. Foco na pós-graduação: Percepção dos docentes perante as exigências da pós-graduação como problemática do cotidiano, tendo em vista } \\
\text { que as cobranças institucionais, sociais e a burocratização dos processos exigem tempo e atenção, encaminhando a docência na pós-graduação } \\
\text { na contramão da graduação. } \\
\text { V. Tecnologias como elemento importante em suas estratégias didáticas: Reconhecem a importância das tecnologias para aproximar os } \\
\text { acadêmicos tanto em relação à dinâmica da sala de aula quanto ao futuro campo de atuação profissional. }\end{array}$ \\
\hline 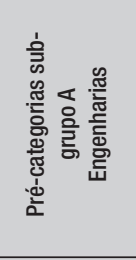 & $\begin{array}{l}\text { VI. Preocupação com o ensino multidisciplinar: Relevância que os docentes da área atribuíram à necessidade de existirem atividades } \\
\text { multidisciplinares. } \\
\text { VII. Ensino articulado ao mundo do trabalho: Característica marcante do grupo de docentes entrevistados; necessidade de exemplos práticos por } \\
\text { meio de atividades em laboratório ou visitas técnicas em espaços apropriados. } \\
\text { VIII. A metodologia tradicional de ensino: Forma mais utilizada em sala de aula, diz respeito às aulas expositivas, como quadro negro e Datashow. Além } \\
\text { disso, tornam-se tradicionais, pois ainda valorizam o docente como detentor de saber, exigindo, portanto, que os acadêmicos escutem sem interferência. } \\
\text { IX. Sentimento de desvalorização do ensino: Fragilidades e problemas diários enfrentados pelos docentes. Dificuldades enfrentadas no cotidiano } \\
\text { acabam por interferir na qualidade do ensino em sala de aula. }\end{array}$ \\
\hline 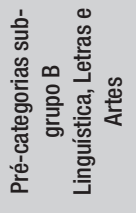 & $\begin{array}{l}\text { X. Foco na área de conhecimento específico: Entendimento dos formadores que envolve a área do conhecimento específico tanto em relação à } \\
\text { sua formação, quanto em relação à formação dos estudantes. } \\
\text { XI. Consciência do papel formativo: Caracterizada pelo modo como os sujeitos entendem o seu papel na formaçã̃o de futuros profissionais. } \\
\text { XII. Relação teoria-prática: Demonstra aspectos do entendimento dos sujeitos que inter-relacionam aspectos teóricos e práticos da formação. }\end{array}$ \\
\hline 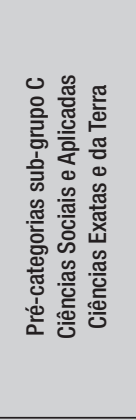 & $\begin{array}{l}\text { XIII. Pano de fundo: } 0 \text { fundamento essencial a partir do qual cada docente se movimenta, ou seja, como o professor sente, pensa e age na sua } \\
\text { atuação docente. } \\
\text { XIV. Rede conceitual: Cada docente elege determinados conceitos que Ihes são significativos. Um processo de elaboração e objetivação da } \\
\text { dinâmica peculiar de cada docente. } \\
\text { XV. Inter-relação interna e externa: Dinâmica relacional que o professor estabelece entre disciplinas e áreas afins. } \\
\text { XVI. Maneira de construir o saber acadêmico: Maneira pela qual o docente constrói a sua movimentação docente. } \\
\text { XVII. Elemento de articulação: Revela que, na movimentação docente, o professor se ampara em algum elemento para construir o saber acadêmico. } \\
\text { XVIII. Impressão das marcas pessoais na docência: Revela marcas pessoais na relação que o professor estabelece com o exercício docente, } \\
\text { bem como sua relação interpessoal com os alunos. } \\
\text { XIX. Concepções próprias da docência: Demonstra as peculiaridades com que o professor concebe a docência. } \\
\text { XX. Percepção do aluno: Como o professor compreende as diversas dimensões do aluno. } \\
\text { XXI. Pontos de tensão: Mostra as dificuldades percebidas pelos professores no exercício docente. Um destes pontos é o equilíbrio entre produção } \\
\text { cientifíca e atividade formativa, e outro é a discrepância entre a própria visão crítica em relação e o funcionamento institucional e acadêmico. }\end{array}$ \\
\hline 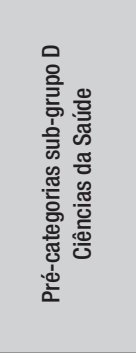 & $\begin{array}{l}\text { XXII. Da especificidade à especialidade - atributos da atuação docente em saúde: Emerge de elementos que surgiram nas narrativas dos professores } \\
\text { ao se referirem à sua profissão de origem, bem como aos conteúdos e conhecimentos científicos que são fundamentais para essa formaçãa, reportando- } \\
\text { se aos conhecimentos das ciências da saúde, como também das ciências sociais e humanas. Consideramos nesta pré-categoria, ainda, as relações } \\
\text { que alguns professores estabelecem dentro de sua especificidade profissional, entretanto com outra especialidade dentro de outra profissão, com outras } \\
\text { profissões da área da saúde e com outras áreas que não da saúde. } \\
\text { XXIII. Vivência profissional do professor da saúde como balizadora da prática pedagógica: Emerge de elementos/aspectos provenientes das } \\
\text { narrativas dos professores entrevistados quando houve diálogo sobre suas percepções a respeito dos conhecimentos necessários para o seu fazer } \\
\text { pedagógico e sobre como este acontece no seu cotidiano. } \\
\text { XXIV. Pluralidade no modo de atuação dos professores da área da saúde no processo de ensino-aprendizagem: Retrata a circularidade dos } \\
\text { modos de atuação dos professores mediante sua constituição a partir das elaborações e [re]elaborações, construções e [re]construções advindas } \\
\text { de sua trajetória profissional e articuladas com o contexto real de trabalho. }\end{array}$ \\
\hline 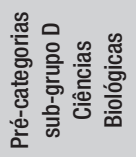 & $\begin{array}{l}\text { XXV. Da especialidade à atuação docente - identidades do professor universitário: Emerge de elementos provenientes das narrativas dos } \\
\text { professores entrevistados quando houve diálogo entre a especialidade e sua identificação como docente. } \\
\text { XXVI. Aprendizagem docente - a busca contínua pelos saberes na docência superior: Emerge de elementos provenientes das narrativas dos } \\
\text { professores entrevistados quando houve diálogo sobre a forma de organizar o saber acadêmico e as estratégias que utilizam em aula. }\end{array}$ \\
\hline
\end{tabular}


A Categoria 1 (conhecimento específico como balizador da docência) denota a centração dos professores nos conhecimentos específicos de sua área de formação e atuação. $\mathrm{Na}$ análise realizada pelos subgrupos, foram identificadas as seguintes pré-categorias: foco na área de conhecimento específico; da especialidade à atuação docente; da especificidade à especialidade. Sobre os conhecimentos específicos no contexto educacional, Bolzan (2006, p. 357-358) considera que são

[...] conhecimentos sobre a matéria a ser ensinada pelo professor. Constitui-se por elementos conceituais e organizacionais dos conteúdos próprios da disciplina, envolvendo ideias, informações, definições, convenções e tópicos gerais, bem como sua estrutura organizacional. Implica no conhecimento das tendências e perspectivas de seu campo específico, incluindo as diferentes interpretações de um mesmo fenômeno e suas relações pelo professor.

Portanto, essa autora leva em consideração que tais conhecimentos dão conta da área específica de que cada disciplina trata, bem como das relações interpretativas realizadas pelo professor para a organização didática desses conhecimentos. Essa constatação tem sido evidenciada por Isaia (2003b), Isaia e Rocha (2013), reforçando os achados atuais. Os achados da pesquisa anterior já denotavam que

[...] o conhecimento específico da área é a base sobre a qual é construída a pedagogia universitária. Esta base é instaurada já no início da carreira docente como um ponto de partida, uma referência, que vai adquirindo as nuances cognitivas e culturais da área em foco. (ISAIA; ROCHA, 2013, p. 29).

Nessa esfera, Morin (2008, p. 18) considera que todo conhecimento comporta necessariamente: “a) uma competência (aptidão para produzir conhecimentos); b) uma atividade cognitiva (cognição), realizando-se em função da competência; c) um saber (resultante dessas atividades)". Assim, segundo o autor, é possível compreender que as competências e atividades cognitivas humanas necessitam de um aparelho cognitivo (cérebro - máquina bio/físico/química); o cérebro necessita da existência biológica de um indivíduo. Sendo esse indivíduo sujeito em uma sociedade tal, as aptidões humanas somente podem se desenvolver no seio de uma cultura que lhe transmitiu valores e costumes. Para Morin (2008, p. 58), o conhecimento é necessariamente:

- Tradução - em signos/símbolos e em sistemas de signos/símbolos (depois, com os desenvolvimentos cerebrais, em representações, ideias, teorias...); - Construção - ou seja, tradução construtora a partir de princípios/regras (programas) que permitem constituir sistemas cognitivos articulando informações/signos/símbolos; - Solução - de problemas, a começar pelo problema cognitivo da adequação da construção tradutora à realidade que se trata de conhecer.

Nessa concepção, é possível compreender que a ideia de Morin (2008) é a de que o conhecimento não reflete a realidade, ele apenas a traduz e a reconstrói em outra realidade. Portanto, o conhecimento específico da área se constitui, inicialmente, como a principal referência da atuação docente. Essa inferência decorre do fato de que os professores se 
voltam prioritariamente para os conhecimentos de sua área, tendo por meta possibilitar aos alunos uma sólida formação no domínio específico (ISAIA, 2003a). Assim, o conhecimento específico da área é a base sobre a qual são construídas pedagogias universitárias, conforme demonstram os seguintes excertos de fala dos sujeitos quando buscam definir qual é a sua área específica de conhecimento e os saberes essenciais dessa área:

Como é uma área especializada dentro da cirurgia e envolve muito tratamento clínico, para o indivíduo exercer essa atividade ele tem que ter um conhecimento muito bom da base da medicina, que é a farmacologia, anatomia, fisiopatologia; tem que ter conhecimento clínico também dos sinais e sintomas das doenças, exames complementares e conduta também, definir a conduta com base na história natural das doenças. Então, envolve bastante conhecimento básico e conhecimento especializado também (S23).

Eu estou concentrado numa área menor da física, uma pequena parte da física que é a física dos sólidos. 0 que eu faço ou tento fazer é estudar como que os sólidos, em geral, se comportam; claro que sempre tentando, se possível, inventar algum tipo novo de sólido que tenha alguma utilidade (S16).

Nesse sentido, viemos concluindo que a área específica de conhecimento pode ser considerada a primeira marca formativa dos professores, considerando que é ela que fornece a base da identidade profissional de cada sujeito, pois constitui sua referência de formação.

Para Bazzo (2007), as profissões se caracterizam pelos conhecimentos específicos e pela configuração de uma prática decorrente das demandas do ofício. Essa autora afirma, ainda, que os profissionais acabam desenvolvendo certos padrões de comportamento, elencando competências e habilidades, bem como valores que se evidenciam por meio de atitudes mais ou menos homogêneas do grupo.

0 que podemos constatar com essas definições a respeito das áreas específicas é que elas vêm repercutindo no modo como esses professores entendem a formação na sua área. Assim, é possível relacionar essas tendências da conceituação da área específica com a organização fragmentada da formação dos futuros profissionais.

Isaia e Bolzan (2009) ainda destacam que, além do domínio de conhecimentos específicos, é importante que os docentes formadores de profissionais invistam na dimensão pedagógica. As autoras consideram que a dimensão pedagógica pode ser construída a partir de um processo reflexivo individual e grupal, pois, sem a consciência da prática de formação que desenvolve, o docente não poderá transformá-la na construção do processo formativo tanto dos seus alunos como do seu próprio. Esse pensamento é compartilhado por Shulman (1989), que demonstra a preocupação com o conhecimento científico, mas também com a sua transposição didática e com a compreensão dos aprendizes. Portanto, não é suficiente que os professores apropriem-se de conhecimentos e conceitos que são próprios de uma formação acadêmica científica; é preciso que consigam comunicar e mediar esses conhecimentos de modo compreensível e significativo aos alunos.

Já a Categoria 2 (rede de saberes da área profissional) sinaliza a marca da prática profissional como balizadora da atuação docente que permite o estabelecimento, na formação, da relação teoria/prática, mundo acadêmico/mundo profissional. 
Sendo assim, a experiência profissional decorre da apropriação de atividades específicas, a partir de um repertório de conhecimentos, saberes e fazeres voltados para o exercício da profissão. Esse repertório, advindo do domínio específico de atuação profissional, orienta a atuação docente e, consequentemente, a formação dos futuros profissionais. Tal dimensão leva em conta, portanto, formar professores para a Educação Básica, formar profissionais para as demais áreas de atuação e gerar conhecimentos sobre os domínios específicos (conhecimento científico e saber acadêmico), bem como a construção do conhecimento de ser professor.

$\mathrm{Na}$ análise realizada pelos subgrupos, foram identificadas as seguintes précategorias: ensino articulado ao mundo do trabalho; relação teoria-prática; saber-saber fazer; elemento de articulação; inter-relação interna e externa; rede conceitual; vivência profissional como balizadora da prática pedagógica; atuação docente alicerçada na experiência prévia como profissional. Com base nestas, construímos a Categoria 2.

Os saberes citados pelos sujeitos deixam evidente a compreensão deles sobre conceitos que são importantes na formação de profissionais na sua área. Essa rede de saberes é compreendida como uma caixa de ferramentas necessárias para a atuação profissional na área. Vejamos os excertos que evidenciam a relevância da rede de saberes profissional mencionada pelos sujeitos:

0 que nós temos, é que trabalhamos com empresas. Essa vivência também é muito importante [...]. Elas nos trazem um conhecimento atual [...]. Se tu fores resolver um problema dentro de uma empresa, esta vai ter que dizer exatamente o que está fazendo. Então esse é o conhecimento atualizado [...]. Então, levamos o campo de trabalho atual, não apenas aquilo que está escrito no livro (S36).

Sempre tento fazer essa ligação física e matemática na engenharia. Na matemática, quando dou aula para matemática, tento fazer uma conexão com a realidade (S18).

Agora, este semestre, eu comecei [...] a trazer pessoas, ex-alunos para dividir um pouco as suas experiências. Trazer alunos egressos para o contexto do curso aproxima os acadêmicos da realidade da profissão (S34).

Especificamente para a área do professor é um elemento fundamental, assim, essas conexões todas, esse tipo de raciocínio para tu entender na temporalidade [...]; é o que pode, de melhor forma, permitir a compreensão do mundo social onde as pessoas estão e aí transformar a cidadania [...]. E, em termos de pesquisa, é uma questão teórica, aí vai depender por onde tu vai adentrar. Mas é uma parte importante, porque é isso que te familiariza com a documentação (S56).

Os excertos demonstram que os docentes não só compreendem a necessidade de os estudantes dominarem conceitos teóricos, mas também se preocupam com competências e habilidades que precisam ser desenvolvidas para a atuação na área. Assim, essa clareza é evidenciada a partir dos discursos relacionados à área específica, e esses excertos destacam, ainda, a formação profissional para a área, agregando especialmente a relação entre teoria e prática viabilizada pela inserção no campo profissional. 
A segunda categoria pode ser relacionada, portanto, ao que Shulman (1989) nomeia de conhecimento pedagógico geral, que abarca os objetivos formativos, de estratégias sobre os processos de aprendizagem e também das competências a serem desenvolvidas na formação.

A Categoria 3 (docência em ação) demarca aspectos considerados pelos professores entrevistados como fundamentais para a organização da sua atuação docente, tendo em vista a formação dos estudantes. Nesse contexto, compreendemos a docência no ensino superior como uma atividade desenvolvida por professores formadores nas diversas áreas de conhecimento que

[...] compreende as atividades desenvolvidas pelos professores, orientadas para a preparação de futuros profıssionais. Tais atividades são regidas pelo mundo de vida e da profissão, alicerçadas não só em conhecimentos, saberes e fazeres, mas também em relações interpessoais e vivências de cunho afetivo, valorativo e ético, o que indica o fato da atividade docente não se esgotar na dimensão técnica, mas remeter ao que de mais pessoal existe em cada professor. (ISAIA, 2006b, p. 374).

Assim, a atuação docente no ensino superior apoia-se na dinâmica da interação de diferentes processos que respaldam o modo como os professores concebem o conhecer, o fazer, o ensinar, e o aprender, bem como o significado que dão a eles. A docência em ação evidencia a articulação dos elementos descritos nas categorias anteriores, traduzidos na forma como os professores organizam seu trabalho para a formação dos estudantes.

$\mathrm{Na}$ análise realizada pelos subgrupos, foram identificadas as seguintes précategorias: maneira peculiar (da área) de construir a docência; preocupação com o ensino multidisciplinar; tecnologias como elemento importante em suas estratégias didáticas; aprendizagem docente; estratégias e formas de organizar a docência; envolvimento na pós-graduação. Com base nestas, construímos a Categoria 3, na qual podemos inferir que o modo peculiar de cada professor atuar na docência depende de suas características pessoais e da área de conhecimento em que atua. Os excertos de fala a seguir evidenciam a docência em ação, ou seja, como os docentes procedem em seu cotidiano pedagógico:

Aulas expositivas. Não dou muito exercícios, sempre tento, na aula, colocar: "nossa aula de hoje vai ser resolver tal problema”; [...] "vamos sentar e traçar uma estratégia de resolução" [...]; "fazer uma tentativa” [...]; “o tema é tal problema e vamos buscar uma estratégia de ataque a ele” (S18).

Então eu penso muito nas rotas que eu utilizo para colocar as informações, e elas, digamos, se encaixarem e se tornarem conhecimento. Eu planejo muito a sequência de coisas que eu falo. Então eu tenho sempre, o meu objetivo, eu entro na sala de aula com o giz na mão e uma ideia na cabeça, como costumo dizer [...]. Eu posso garantir que cada aula que eu dou não é igual à anterior, e eu estou sempre em busca de uma maneira mais eficiente de fazer, de executar aquela tarefa como professor [...] (S35).

[...] quando eles não sabem, eu preciso criar a estrutura do conhecimento deles e eles criam esses conceitos, daí eu tenho que voltar atrás, ensinar eles o que é, qual artéria é aquela, a anatomia, qual a causa natural da doença, daquela patologia, o diagnóstico (S23). 
[...] eu tenho uma estratégia de estudo, eu tenho uma sequência lógica. Tu inicias aquele ponto de conceituação, de entendimento geral, porque funciona assim, para depois ir para os pontos específicos. E depois finalmente abordar as correlações clínico-cirúrgicas com a anatomia (S28).

É possivel constatar que os docentes expressam estratégias que consideram relevantes para que os estudantes se apropriem dos conceitos necessários para sua formação profissional. Sobre esse aspecto, Behrens (2010) entende que todas as áreas de conhecimento são influenciadas pelos paradigmas da ciência e que a compreensão desses paradigmas nos auxilia a entender a proposta para a formação. Portanto, as estratégias utilizadas pelos sujeitos para operacionalizar suas concepções sobre a formação dos profissionais está relacionada com a sua própria formação e com a sua visão de mundo construída a partir da área.

Essa categoria envolve o que Shulman (1968) denomina conhecimento pedagógico do conteúdo, que é de fundamental importância para a atuação docente, pois é dele que depende o processo de ensino e de aprendizagem. A docência em ação está diretamente relacionada ao conhecimento pedagógico do conteúdo, pois este abrange o conteúdo específico, o conteúdo pedagógico geral e o modo como os docentes entendem as finalidades de ensinar determinado conteúdo. Ou seja, abrange tudo o que se relaciona ao que é importante que os alunos aprendam para a profissão na qual estão se formando.

Como supra-categoria, emergiu a dimensão pessoal da docência, entendida como o núcleo fundante que perpassa todas as demais categorias, demarcando a atuação docente. Dessa forma, tal supra-categoria converge para os achados da nossa pesquisa sobre os Ciclos de Vida Profissional Docente, ${ }^{4}$ na medida em que enfatiza a consciência da docência marcada pela dimensão humana. A sensibilidade humana dos professores, assim configurada, reverte para uma concepção de docência em que o componente ético, cognitivo e emocional do saber profissional docente favorece que os estudantes atinjam a sua formação.

Dimensão Pessoal da Docência: decorre do fato dos docentes serem capazes de se perceberem como uma unidade em que a pessoa e o profissional determinam o modo de ser professor. Eles estão inteiros na docência, constituindo-a pelas marcas da vida e da profissão. Compreende, ainda, o duplo movimento que os professores realizam em relação a suas atividades docentes, ou seja, ao mesmo tempo em que eles se reconhecem como sujeitos dessas atividades, são capazes de se distanciarem e fazer com que elas se tornem objetos de suas reflexões. (ISAIA, 2006a, p. 376).

A docência é uma atividade essencialmente humana e requer do professor, embora seja ele um profissional de área específica, uma disposição para conviver com pessoas, bem como entender essas pessoas como sujeitos em formação. Para tanto, a dimensão pessoal da docência imbricada nesse processo tem uma marca forte na formação dos futuros profissionais. Vejamos os excertos de fala de alguns dos sujeitos que deixam explícita a preocupação com a dimensão pessoal da docência:

4- Edital MCT/CNPq 15/2007. Produtividade em Pesquisa, PQ/2006. 
[...] a instituição não tem mais a necessidade de instrumentos; ela tem necessidade de alma de professor dentro de sala de aula, e se ela não tiver isso agora, ela realmente morre (S35).

Bom, eu acho que a minha experiência aqui na universidade não é uma coisa que a gente possa pontuar como regra. Eu sempre me senti bem, estou aqui como professor formador e eu gosto de dar aula, e isso faz com que a gente pense nesses vinte e poucos anos em como implementar melhorando as aulas de graduação a todos os anos... são diferentes, mas, então... Eu acho que, na minha prática docente, a minha experiência de pesquisa é extremamente positiva, mas não posso dizer que isso é uma regra (S53).

A atuação do docente na educação superior não é restrita à sala de aula, tampouco à pesquisa ou ao administrativo. 0 docente precisa desenvolver essas atividades de forma concomitante e complementar. Para Isaia (2006b, p. 63),

[...] a docência superior é um processo complexo que se constrói ao longo da trajetória docente e que esta envolve, de forma intrinsecamente relacionada, a dimensão pessoal, a profissional e a institucional. Na tessitura das três, dá-se a constituição do ser professor.

É sob esse olhar que consideramos que a compreensão que se tem de seu processo formativo envolve o entendimento de que ele é de natureza social, pois os professores se constituem como tal em atividades interpessoais. Os esforços que eles realizam para aquisição, desenvolvimento e aperfeiçoamento de competências profissionais subentendem um grupo interagindo, centrado em interesses e necessidades comuns, em um contexto institucional concreto.

Assim sendo, destacamos que a dimensão pessoal da docência pode permitir uma transposição do conhecimento específico, a partir de um olhar pedagógico baseado nas práticas de ensino de cada área. Entendemos que essa dimensão humana se constitui como um desafio na formação de docentes para a atuação no ensino superior, pois transcende as exigências para o ingresso na carreira e depende, fundamentalmente, de uma disposição pessoal para tal.

\section{Considerações finais}

Tendo em vista a trama formativa constituída pelas categorias elencadas e as áreas de conhecimento, é possível entendermos a pedagogia universitária se contituindo a partir da tensão entre os conhecimentos científicos da área e os conhecimentos pedagógicos. Tal compreensão indica que os saberes acadêmicos são construídos no enfrentamento dessas tensões e na constante busca de convergência entre os interesses da área específica, da área pedagógica e da dinâmica do mundo do trabalho.

Assim, a especificidade da pedagogia universitária se traduz pela possibilidade de falarmos em diferentes pedagogias, levando em conta os parâmetros epistemológicos e pedagógicos que podem se expressar no que denominamos conhecimento pedagógico do conteúdo. 
A principal conclusão desta pesquisa é que, levando em conta as distintas áreas de conhecimento, não há tanta diferença em relação à atuação docente, mas, apesar disso, ela é demarcada a partir da área de conhecimento dos docentes. Ou seja, o conhecimento pedagógico se ajusta às diferentes áreas do conhecimento, tomando corpo como um conhecimento pedagógico específico. Isso acaba por afirmar e imprimir uma característica de estatuto epistemológico próprio do conhecimento pedagógico. Nesse sentido, o maior desafio para os docentes das distintas áreas de conhecimento é a articulação do específico da área com o pedagógico na atuação docente e na formação dos profissionais. Consideramos, ainda, que a condução da aprendizagem depende fundamentalmente dessa articulação, por isso justifica-se o uso da expressão pedagogias universitárias (no plural).

Por fım, esta pesquisa nos permitiu a vivência de um espaço de formação de pesquisadores no contexto de um grupo de pesquisa e destacamos que, embora o estudo tivesse seu foco nos sujeitos enquanto docentes das diversas áreas, os pesquisadores envolvidos também eram oriundos de áreas distintas, favorecendo a formação para a pesquisa acadêmica. 0 fato de pesquisadores de diferentes áreas do conhecimento fazerem parte desse grupo favoreceu a diversidade de formas de interpretação e de organização da análise dos achados da pesquisa. Tal diversidade traduziu diferentes enfoques e formas de conceber a interpretação qualitativa dos resultados, o que ampliou e qualificou a análise e a produção das categorias explícitas neste trabalho.

\section{Referências}

ARNAUS, Remei. Voces que cuentam y voces que interpretam. In: LARROSA, Jorge et al. Déjame que te cuente: ensaios sobre narrativa y educación. Barcelona: Laertes, 1995. p. 61-79.

BAUER, Martin; GASKELL, George (Org.). Pesquisa qualitativa com imagem, texto e som: um manual prático. Tradução de Pedrinho Guareschi. Petrópolis: Vozes, 2004.

BAZZO, Vera Lúcia. Dilemas da profissionalidade docente na educação superior: entre o cientista e 0 mestre. In: FRANCO, Maria Estela D. P.; KRAHE, Elizabeth D. (Org.). Pedagogia universitária e áreas de conhecimento. Porto Alegre: Edipucrs, 2007. p. 57-72.

BEHRENS, Marilda Aparecida. Docência universitária num paradigma da complexidade: possibilidades de formação continuada no stricto sensu. Revista Diálogo Educacional, Curitiba, v. 10, n. 29, p. 27-44, jan./ abr. 2010.

BOLIVAR, Antonio; DOMINGO, Jesus; CRUZ, Manuel Fernández. La investigación biográfica-narrativa em educación. Madrid: La Muralla, 2001.

BOLZAN, Doris P. Vargas. Conhecimento docente específico. In: MOROSINI, Marilia C. (Org.) Enciclopédia de pedagogia universitária: glossário. v. 2. Brasília, DF: INEP, 2006. p. 357-358.

CONNELLY, D. Jean; CLANDININ, F. Michael. Relatos de experiencia e investigación narrativa. In: LARROSA, Jorge et al. Déjame que te cuente. Barcelona: Alertes, 1995. p. 11-59. 
GAMBOA, Silvio S. Epistemologia da pesquisa em educação. Práxis Educativa, Ponta Grossa, v. 4, n. 1, p. 9-19, jan./jun. 2009.

GOODSON, Ivor. Profesorado e historias de vida: um campo de investigación emergente. In: GO0DSON, Ivor (Ed.). Historias de vida del profesorado. Barcelona: Octaedro, 2004. p. 45-62.

HABERMAS, Jürgen. Teoria de la acción comunicativa: racionalidad de la acción y racionalización social. tomo I. Madrid: Taurus, 1987a.

HABERMAS, Jürgen. Teoria de la acción comunicativa: crítica de la razón funcionalista. tomo II. Madrid: Taurus, 1987b.

ISAIA, Sílvia Maria de Aguiar. Desafios à docência superior: pressupostos a considerar. In: RISTOFF, Dilvo; SEVEGNANI, Palmira (Org.). Docência na educação superior. Brasília, DF: INEP, 2006a. (Educação superior em debate, v. 5). p. 63-84.

ISAIA, Sílvia Maria de Aguiar. Formação do professor de ensino superior: tramas na tessitura. In: MOROSINI, Marilia C. (Org.). Enciclopédia de pedagogia universitária. Porto Alegre: Fapergs/RIES, 2003a. p. 241-251.

ISAIA, Sílvia Maria de Aguiar. Professor de licenciatura: concepções de docência. In: MOROSINI, Marilia C. (Org.). Enciclopédia de pedagogia universitária. Porto Alegre: Fapergs/RIES, 2003b. p. 263-277.

ISAIA, Sílvia Maria de Aguiar. Verbetes. In: MOROSINI, Marília (Ed.). Enciclopédia de pedagogia universitária: glossário. v. 2. Brasília, DF: INEP, 2006b. p. 367, 368, 369, 371, 373, 376, 377.

ISAIA, Sílvia Maria de Aguiar; BOLZAN, Doris P. Vargas. Trajetórias da docência: articulando estudos sobre os processos formativos e a aprendizagem de ser professor. In: ISAIA, Sílvia Maria de Aguiar; BOLZAN, Doris P. Vargas (Org.) Pedagogia universitária e desenvolvimento profissional docente. Porto Alegre: Edipucrs, 2009. p. 121-143.

ISAIA, Sílvia Maria de Aguiar; ROCHA, Adriana Moreira. Os movimentos da docência superior: construções possíveis nas diferentes áreas de conhecimento. [S. I.: s. n.], 2013. Relatório de pesquisa, CNPq, modalidade $\mathrm{APQ}$.

McEWAN, Hunter. Las narrativas en el estudio de la docência. In: McEWAN, Hunter; EGAN, Kieran (Comp.) La narrativa en la enseñanza, el aprendizaje y la investigación. Buenos Aires: Amorrortu, 1998. p. 236-259.

MORAES, Roque. Uma tempestade de luz: a compreensão possibilitada pela análise textual discursiva. Ciência \& Educação, Bauru, v. 9, n. 2, p. 191-211, 2003.

MORAES, Roque; GALIAZZI, Maria do Carmo. Análise textual discursiva. ljuí: Unijuí, 2007.

MORIN, Edgar. 0 método 3: conhecimento do conhecimento. Tradução de Juremir Machado da Silva. 4. ed. Porto Alegre: Sulina, 2008.

RICOEUR, Paul. 0 conflito da interpretação: ensaios de hermenêutica. Rio de Janeiro: Imago, 1978. 
SHULMAN, Lee S. Knowledge and teaching: the foundations of the new reform. Harvard Educational Review, Cambridge, v. 57, n. 1, p. 1-21, 1987.

SHULMAN, Lee S. Paradigmas y programas de investigación en el studio de la enseñanza: una perspective contemporanea. In: WITTROCK, Merlin. La investigación de la enseñanza: enfoques, teorias y métodos. Barcelona: Paidós, 1989. p. 9-84.

SHULMAN, Lee S. Those who understand: knowledge growth in teaching. Educational Researcher, Washington, DC, v. 15, n. 2, p. 4-14, 1968.

VISCOVINI, Ronaldo Celso et al. Recursos pedagógicos e atuação docente. In: CONGRESSO NACIONAL DE EDUCAÇÃO (EDUCERE), 9., 2009, Curitiba. Anais... Curitiba: PUC-PR, 2009. p. 1230-1238.

Recebido: 28.03.2017

Revisões: 23.06.2017

Aprovado em: 04.07.2017

Greice Scremin é doutora em Educação, professora adjunta do Centro Universitário Franciscano e pesquisadora do Grupo de Pesquisa Trajetórias de Formação (GTFORMA).

Silvia Maria de Aguiar Isaia é doutora em Educação, professora adjunta do Centro Universitário Franciscano, docente da Universidade Federal de Santa Maria e pesquisadora/ coordenadora do Grupo de Pesquisa Trajetórias de Formação (GTFORMA). 